\title{
Estimation of the Regional Evaporative Fraction over the Tibetan Plateau Area by Using Landsat-7 ETM Data and the Field Observations
}

\author{
Yaoming MA \\ Institute of Tibetan Plateau Research, Chinese Academy of Sciences, Beijing, China \\ School of Geography and Remote Sensing, Beijing Normal University, Beijing, China \\ Cold and Arid Regions Environmental and Engineering Research Institute, Chinese Academy of Sciences, \\ Lanzhou, China \\ Minhong SONG \\ Cold and Arid Regions Environmental and Engineering Research Institute, Chinese Academy of Sciences, \\ Lanzhou, China

\section{Hirohiko ISHIKAWA} \\ Disaster Prevention Research Institute, Kyoto University, Kyoto, Japan \\ Kun YANG, Toshio KOIKE \\ Department of Civil Engineering, University of Tokyo, Tokyo, Japan

\section{Li JIA} \\ Alterra, Wageningen University and Research Center, Wageningen, The Netherlands

\section{Massimo MENETI} \\ Laboratoire des Sciences de l'Image, de l'Informatique et de la Télédétection (LSIIT), Université Louis Pasteur, \\ France \\ and

\section{Zhongbo SU} \\ International Institute for Geo-Information Science and Earth Observation, The Netherlands \\ (Manuscript received 14 February 2006, in final form 1 November 2006)
}

Corresponding author: Yaoming Ma, Institute of

Tibetan Plateau Research, Chinese Academy of

Sciences, 18 Shuangqing Road, P.O. Box 2871, Bei-

jing 100085, P. R. China.

Email: ymma@itpcas.ac.cn

(C) 2007, Meteorological Society of Japan 


\begin{abstract}
This study proposed a parameterization methodology based on Landsat-7 ETM data and field observations and tested it for deriving an evaporative fraction $(E F)$ over a heterogeneous landscape. As a case study, the methodology was applied to the experimental area of CAMP/Tibet located on the central Tibetan Plateau. Four scenes of Landsat-7 ETM data were used in the study. Scenes of 9 June 2002 and 28 August 2002 were selected as case examples of summer and autumn, respectively; the scene of 2 December 2002 was selected as a winter case; and 24 March 2003 was selected as a spring case (or pre-monsoon period). To validate the proposed methodology, the Landsat-7 ETM derived EFs were compared to ground-measured values in four different months that spanned a wide range of surface conditions and surface features. This comparison revealed that the predictions were in good accordance with the ground measurements with absolute percent differences of less than 9.5\%. It was concluded that the proposed methodology successfully facilitates the retrieval of EF using Landsat-7 ETM data and field observations over the study area.
\end{abstract}

\section{Introduction}

Fluxes of sensible heat and evapotranspiration $(E T)$ between the land surface and atmosphere over the Tibetan Plateau play an important role in the Asian Monsoon system, which in turn is a major component involved in the energy and water cycles of the global climate system. The study of heat and ET fluxes between the land surface and atmosphere has thus been of paramount importance for the Coordinated Enhanced Observing Period (CEOP) Asia-Australia Monsoon Project (CAMP) on the Tibetan Plateau (CAMP/Tibet, 2001-2005) (e.g., Ma et al. 2003a; Ma et al. 2005). This project included an intensive observation period (IOP) in addition to the longer-term observation at CAMP/Tibet. The experimental region, about $150 \times 250 \mathrm{~km}^{2}$, includes a variety of land surfaces such as a large area of grassy marshland, some desertification grass-land areas, many small rivers and several lakes (Fig. 1). The large amount of data collected during these campaigns provides the best opportunity to study energy and water cycles over the Tibetan Plateau.

Numerous studies have detailed land surface sensible heat and ET fluxes over the CAMP/ Tibet area in the past several years (e.g., Yang et al. 2002; Ma et al. 2002a; Ma et al. 2003a; Yang et al. 2003; Yang et al. 2004; Choi et al. 2004; Zuo et al. 2005; Ma et al. 2005). These studies were, however, at point-level or the local-patch-level. Since areal rather than pointwise information of land-surface atmosphere interaction is required, the aggregation of the point-scale results to a regional scale is therefore necessary.
Remote sensing from satellites however offers the possibility to derive regional distributions of land surface heat fluxes and ET over heterogeneous land surfaces in combination with sparse field experimental stations. Our purpose in this study is to estimate the regional distribution of $E T$ with the aid of high resolution $(30 \times 30 \mathrm{~m})$ Landsat-7 ETM data and insitu data. ET from land is essential for understanding climate dynamics and ecosystem productivity (e.g., Churkina et al. 1999) and it also has applications in areas such as water resource management. We will introduce "evaporative fraction $(E F)$ " as an index for $E T$ after Shuttleworth et al. (1989). EF is defined here as:

$$
\Lambda=\frac{\lambda E}{H+\lambda E}=\frac{\lambda E}{R_{n}-G_{0}}
$$

Where $H$ is the sensible heat flux, $\lambda E$ the latent heat flux, $R_{n}$ net radiation flux and $G_{0}$ the soil heat flux.

Our goal is not estimation of $E T$ but that of rather $E F$ in the CAMP/Tibet area. This is due to two reasons. First, $E F$ is more suitable as an index for surface moisture condition than $E T$. Because $E T$ is a function not only of the land surface conditions (e.g., soil moisture and vegetation) but also of surface available energy $R_{n}-G_{0}(=H+\lambda E), E T$ cannot easily interpret soil moisture conditions or drought status. Contrarily, $E F$ can be more directly related to these land surface conditions. Second, $E F$ is useful for scaling up instantaneous observations to longer time periods. Except for geostationary satellites, remote sensing observations of the land surface are often only available for a very 


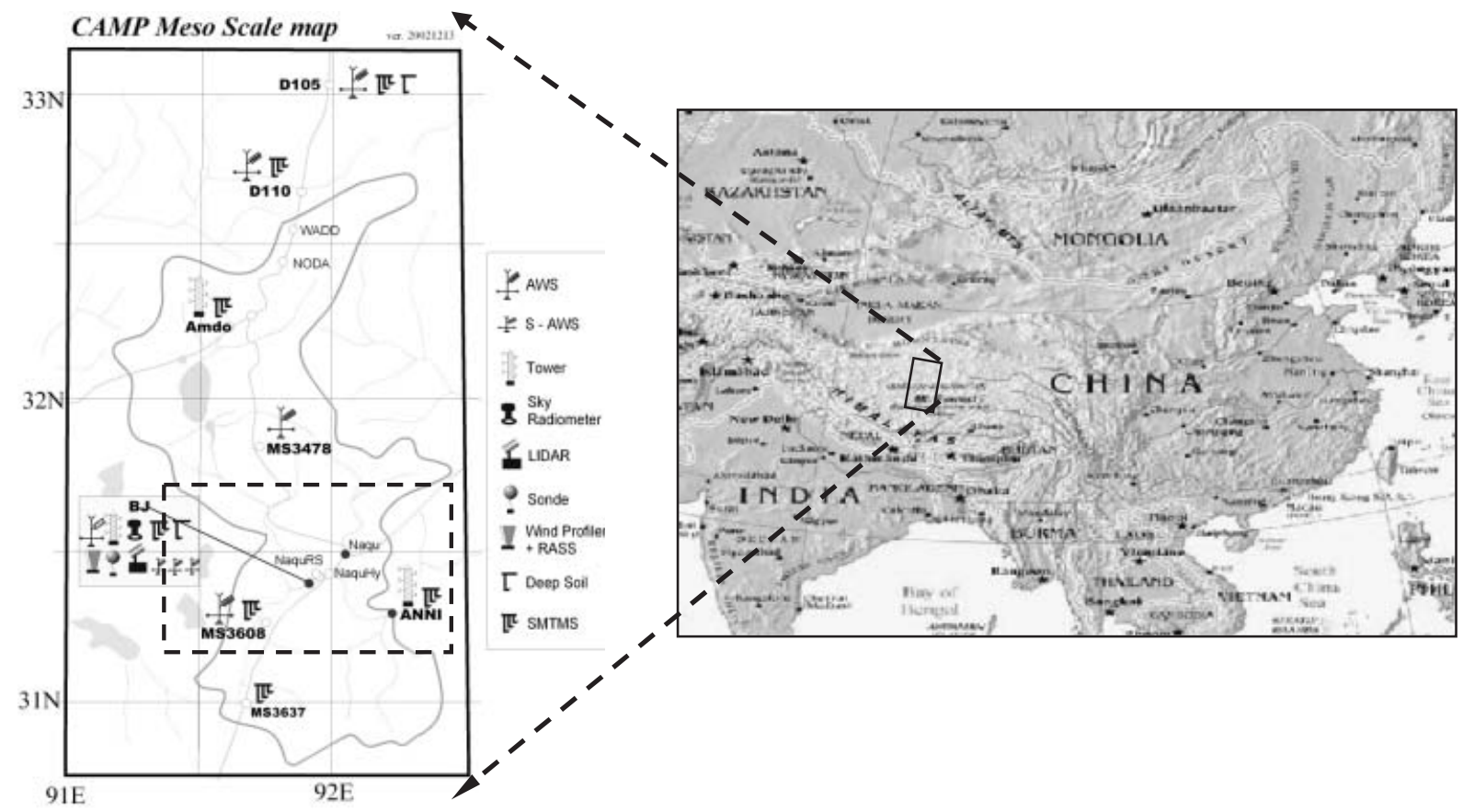

Fig. 1. Geographic map and site layout for CAMP/Tibet.

brief period of the day. ET, however, can change drastically during a day because of changes in the angle of the sun and from cloud coverage. Therefore, even if we can accurately estimate $E T$ at the moment of satellite overpass, it cannot be directly related to daily or daytime average $E T$. Contrarily, $E F$ is well known to be nearly constant during most of the daytime period (e.g., Shuttleworth et al. 1989; Sugita and Brutsaert 1991; Crago 1996). We have found that $E F$ is nearly constant from sunrise to sunset at the BJ station of CAMP/ Tibet during one day of both the dry season (18 April 2004) and the wet season (12 June 2004) (see Fig. 2). Therefore, if we can estimate daily or daytime average $R_{n}-G_{0}$, we can estimate daily or daytime average $E T$ from Eq. 1 by using instantaneous $E F$ derived by satellite.

In this study, the regional distribution of $E F$ will be estimated using a combination of Landsat-7 ETM observations and ground-based data and validated using eddy covariance measurements of latent heat exchange. We first describe the methodology and the data used in Section 2. The application of the methodology to the CAMP/Tibet period is presented in Section 3, where the distributions of $E F$ are esti- mated for four different phases, spring, summer, autumn and winter by using four scenes of Landsat-7 ETM data. Discussions are also presented in this section.

\section{Data and methodology}

\subsection{Data}

The Landsat-7 Enhanced Thematic Mapper (ETM) provides a spectral radiance in seven narrow bands, with a spatial resolution of about $30 \times 30 \mathrm{~m}$ for three visible bands (Bands $1,2,3$ ), three near infrared bands (Bands 4, 5, 7 ), and $60 \times 60 \mathrm{~m}$ for the thermal infrared Band 6. It is best to select the satellite data on clear days to study the distribution and intermonthly variation of $E F$ and energy budget components. Unfortunately, it is rather difficult to select this kind of satellite data over the Tibetan Plateau area because of the strong convective clouds when Landsat-7 ETM observations take place. Only four scenes of ETM images could be selected during the intensive observation period of the CAMP/Tibet. They are at 10:00 (local time), 9 June 2002 (summer), 28 August 2002 (autumn), 2 December 2002 (winter) and 24 March 2003 (spring) over the CAMP/Tibet area. 


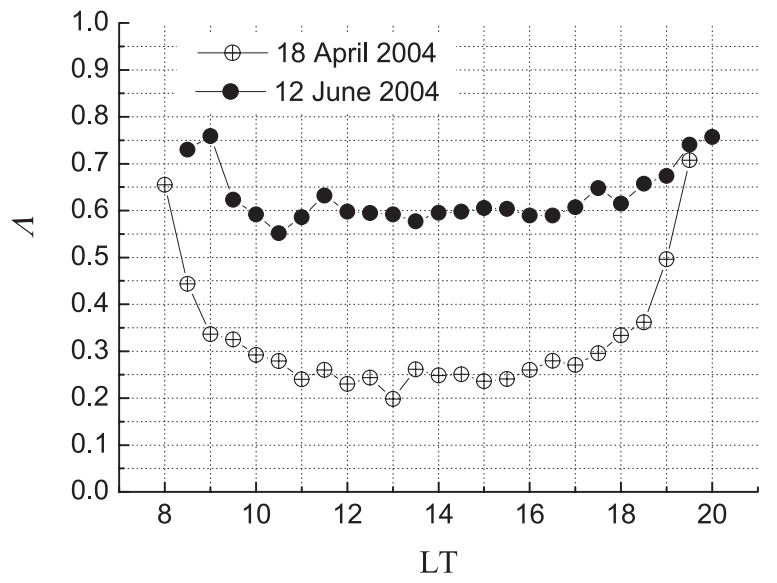

Fig. 2. Diurnal variation of evaporative fraction at BJ station of CAMP/Tibet.

The most relevant field data, collected at the CAMP/Tibet surface stations to support the parameterization of EF and analysis of ETM images in this paper, consist of surface radiation budget components, surface radiation temperature, surface reflectance, vertical profiles of air temperature, humidity, wind speed and direction measured at the Automatic Weather Stations (AWSs), Atmospheric Boundary Layer (ABL) tower, radio-sonde, turbulent fluxes measured by the eddy-correlation technique, soil heat flux, soil temperature profiles, soil moisture profiles, and the vegetation state.

\subsection{Theory and scheme}

The general concept of the methodology of determining $E F$ is shown in Fig. 3. It has two steps: The first one is to determine the surface variables (surface reflectance and surface temperature) and surface heat fluxes (net radiation flux, surface soil heat flux, sensible heat flux and latent heat flux). The second is to estimate the $E F$ by Eq. 1 using the derived sensible heat and latent heat fluxes.

\section{a Surface heat fluxes}

The regional distribution of net radiation flux $\left(R_{n}\right)$, soil heat flux $\left(G_{0}\right)$, sensible heat flux $(H)$ and latent heat flux $(\lambda E)$ over heterogeneous land surface of the CAMP/Tibet area can be derived by combining the Landsat-7 ETM data with field observations. The methodology is same as the heat fluxes derived from the NOAA/AVHRR data, except the determination of soil heat flux (Ma et al. 2003b). The methodology is as follows.

\section{Net radiation}

The regional net radiation flux can be derived from

$$
\begin{aligned}
R_{n}(x, y)= & \left(1-r_{0}(x, y)\right) \bullet K_{\downarrow}(x, y) \\
& +L_{\downarrow}(x, y)-\varepsilon_{0}(x, y) \sigma T_{s f c}^{4}(x, y)
\end{aligned}
$$

where $\varepsilon_{0}(x, y)$ is surface emissivity, $K$ represents the short-wave $(0.3-3 \mu \mathrm{m})$, and $L$ is the long wave $(3-100 \mu \mathrm{m})$ radiation components, respectively. Surface reflectance, $r_{0}(x, y)$, can be derived from integrated hemispherical planetary reflectance (e.g., Koepke et al. 1985; Menenti et al. 1989; Bastiaanssen 1995; Wang et al. 1995; Ma et al. 1999). However the linear regression relationships between surface reflectance, $r_{0}(x, y)$, and integrated hemispherical planetary reflectance, $r_{p}(x, y)$, are in doubt, because: 1) the ground measurement is only a point value, while satellite pixels are the average of many point values, and 2) fewer ground observation data have a coincident relationship with satellite data (Wen 1999). A four-stream radiative transfer assumption for atmospheric correction in solar spectral bands (Verhoef 1997) is introduced to derive the surface reflectance over the CAMP/Tibet area in this study. This means that the distribution of land surface reflectance can be derived as (Ma and Tsukamoto 2002b)

$$
r_{s}^{b}(x, y)=\sum_{i=1}^{7(i \neq 6)} w(i) r_{s}^{i}(x, y)
$$

where $w(i)$ is the weight of each band at surface, $r_{s}^{b}$ is the broadband surface reflectance, $r_{s}^{i}$ is the band reflectance of Landsat-7 ETM.

The incoming short-wave radiation flux, $K_{\downarrow}(x, y)$, in Eq. 2 can be derived from the radiative transfer model MODTRAN (Kneizys et al. 1996), where atmospheric short-wave transmittance, $\tau_{s w}$, is obtained, and the atmospheric profiles of air temperature and humidity measurements measured by a radio sonde system have been used here. Hence $K_{\downarrow}(x, y)$ can be obtained as

$$
K_{\downarrow}(x, y)=\tau_{s w} K_{T O A}^{\downarrow}(x, y)
$$

where the regional variation of radiation flux perpendicular to the top of atmosphere, 


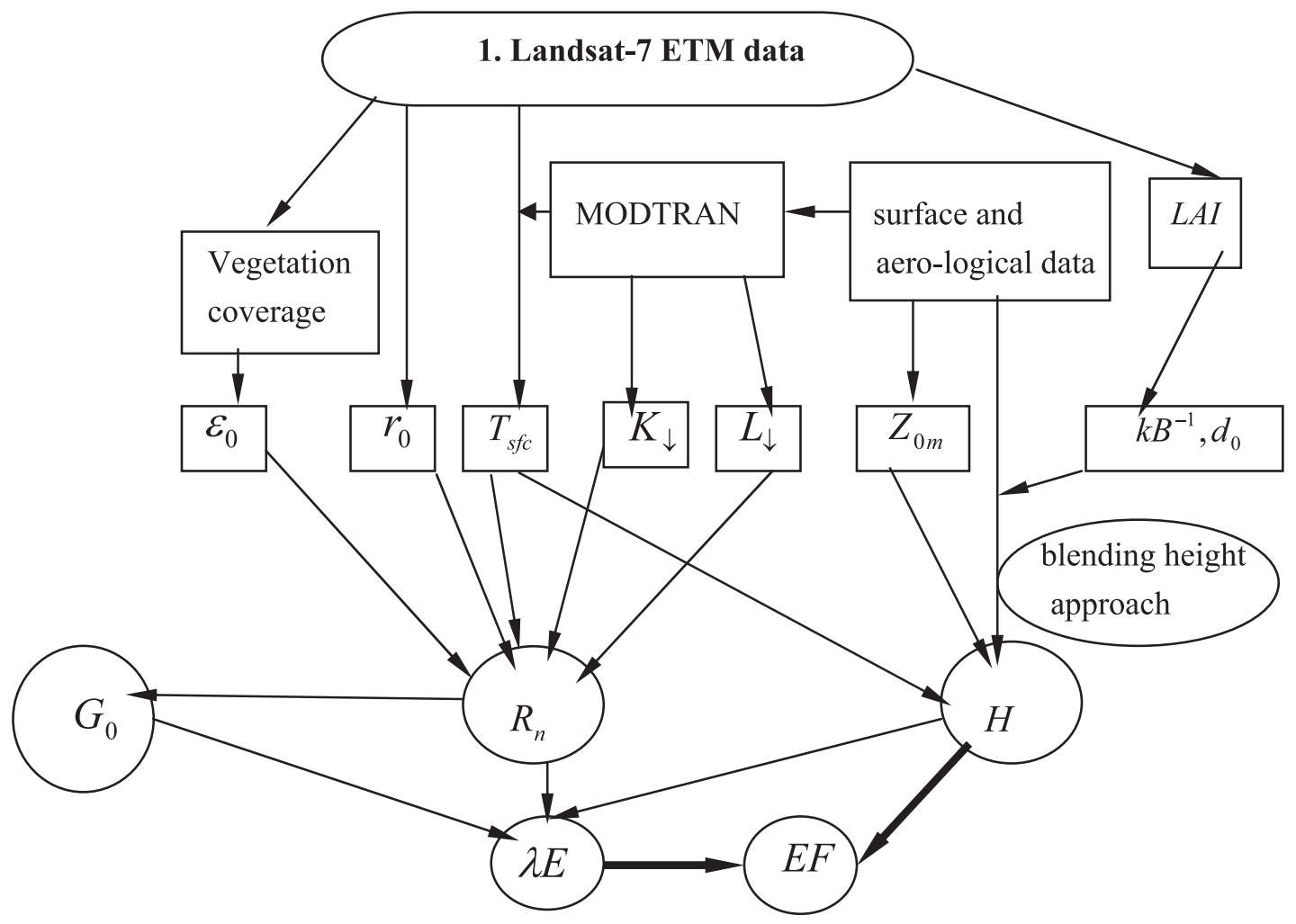

Fig. 3. Diagram of the parameterization procedure for evaporative fraction $(E F)$ by combining Landsat-7 ETM data with field observations.

$K_{T O A}^{\downarrow}(x, y)$, is a spectrally integrated form of inband radiation flux density perpendicular to the top of atmosphere, $K_{T O A}^{\downarrow}(b)$, and

$$
K_{T O A}^{\downarrow}(x, y)=\frac{K_{e x o}^{\downarrow}(b) \cos \theta_{\text {sun }}(x, y)}{d_{s}^{2}}
$$

where $K_{e x o}^{\downarrow}(b)$ is the averaged in-band solar exoatmospheric irradiance undisturbed by $\theta_{\text {sun }}$ being zero, $b$ is abbreviation of in-band, $d_{s}$ is the ratio of the earth-sun distance to the average distance, $\theta_{\text {sun }}$ is sun zenith angle.

The incoming long-wave radiation flux, $L_{\downarrow}(x, y)$, in Eq. 2 can be derived from MODTRAN directly as well (Ma and Tsukamoto 2002b). Surface temperature, $T_{s f c}(x, y)$, in Eq. 2 can be derived from Landsat-7 ETM thermal infrared band-6 spectral radiance (Ma and Tsukamoto 2002b). Because Band 6 (10.2-12.5 $\mu \mathrm{m})$ is relatively transparent to radiation transfer in the atmospheric layer under a cloud-free sky, the absorption in this band is relatively small except under turbid weather conditions, the main substance of continuous absorption are water vapor and aerosol. That is, the distribution of land surface temperature is obtained as (Ma and Tsukamoto 2002b)

$$
T_{s f c}(x, y)=\varepsilon_{0}(x, y)^{-1 / 4} T^{B}(x, y)
$$

where $\varepsilon_{0}(x, y)$ is surface emissivity, it can be derived from vegetation coverage $P_{v}$ (Valor and Caselles 1996), i.e.:

$$
\begin{aligned}
\varepsilon_{0}(x, y)= & \varepsilon_{v}(x, y) P_{v}(x, y)+\varepsilon_{g}(x, y)\left(1-P_{v}(x, y)\right) \\
& +4\langle d \varepsilon\rangle\left(1-P_{v}(x, y)\right) P_{v}(x, y)
\end{aligned}
$$

where $\varepsilon_{v}(x, y)=0.985( \pm 0.007)$ and $\varepsilon_{g}(x, y)=$ $0.960( \pm 0.010)$ are surface emissivity for full vegetation and bare soil respectively, $\langle d \varepsilon\rangle=$ $0.015( \pm 0.008)$ is the error item (Valor and Caselles 1996), and vegetation coverage (Carlson and Ripley 1997)

$$
P_{v}(x, y)=\left[\frac{N D V I(x, y)-N D V I_{\min }}{N D V I_{\max }-N D V I_{\min }}\right]^{2}
$$


where $N D V I_{\min }$ and $N D V I_{\max }$ are the $N D V I$ values for bare soil and full vegetation respectively.

\section{Soil heat flux}

The soil heat flux can be determined from knowledge of the soil temperature profile and the resistance to heat transfer in the soil (e.g., Choudhury and Montheith 1988). However, this approach cannot be used with satellite observations due to the difficulty in determining soil temperature at depth and soil resistance to heat transfer from remote sensing observations (e.g., Bastiaanssen 1995; Ma et al. 2002c). As an alternative, many investigations have shown that the mid-day $G_{0} / R_{n}$ ratio, $\Gamma$, is reasonably predictable from special vegetation indices (Daughtry et al. 1990). $\Gamma$ can be considered as a function $F$ which relates $G_{0} / R_{n}$ to other variables (Ma and Tsukamoto 2002b). Some researchers have concluded that $G_{0} / R_{n}=\Gamma=F(N D V I) \quad$ (Clothier et al. 1986; Kustas and Daughtry 1990). A better ratio of $G_{0} / R_{n}=\Gamma=F\left(r_{0}, T_{s f c}, N D V I\right)$ was also found (e.g., Choudhury et al. 1987; Menenti et al. 1991; Bastiaanssen 1995). The relationship between $G_{0}(x, y)$ and $R_{n}(x, y)$ derived in the Tibe$\tan$ Plateau area (Ma et al. 2002c) will be used to determine regional soil heat flux over the CAMP/Tibet area here, and

$$
\begin{aligned}
G_{0}(x, y)= & 0.35462( \pm 0.00235) R_{n}(x, y) \\
& -47.79( \pm 0.7005)
\end{aligned}
$$

with a correlation coefficient $r=0.93$ and standard deviation $\mathrm{SD}=36.32234$ (field data number $N=3619$ ). The accuracy of Eq. 9 will increase with the number of the field data.

\section{Sensible heat flux}

The regional distribution of sensible heat flux is calculated from

$$
H(x, y)=\rho C_{p} \frac{T_{s f c}(x, y)-T_{a}(x, y)}{r_{a}(x, y)}
$$

where aerodynamic resistance is

$$
\begin{aligned}
r_{a}(x, y)= & \frac{1}{k u_{*}(x, y)}\left[\ln \left(\frac{z-d_{0}(x, y)}{Z_{0 m}(x, y)}\right)\right. \\
& \left.+k B^{-1}(x, y)-\psi_{h}(x, y)\right]
\end{aligned}
$$

where $k$ is Von-Karman constant, $u_{*}$ is friction velocity, $z$ is reference height, $d_{0}$ is zero-plane displacement height, $Z_{0 m}$ is the aerodynamic roughness, $k B^{-1}$ is the excess resistance for heat transportation, $\psi_{h}$ is the stability correction function for heat. The friction velocity, $u_{*}$, can be derived from

$$
\begin{gathered}
u(x, y)=\frac{u_{*}(x, y)}{k}\left[\ln \left(\frac{z-d_{0}(x, y)}{Z_{0 m}(x, y)}\right)\right. \\
\left.-\psi_{m}(x, y)\right]
\end{gathered}
$$

where $\psi_{m}$ is the stability correction function for momentum.

From Eqs. 10, 11, and 12

$$
\begin{aligned}
& H(x, y) \\
& =\rho C_{p} k^{2} u(x, y) \frac{T_{s f c}(x, y)-T_{a}(x, y)}{\left[\ln \frac{z-d_{0}(x, y)}{Z_{0 m}(x, y)}+k B^{-1}(x, y)-\psi_{h}(x, y)\right] \cdot\left[\ln \frac{z-d_{0}(x, y)}{Z_{0 m}(x, y)}-\psi_{m}(x, y)\right]}
\end{aligned}
$$

One approach to simulate sensible heat flux on a large scale is to scale-up or aggregate the regional sensible flux by a weighted average of the contributions from different surface elements, based on the principle of flux conservation. In this study, we propose a method of "blending height" to derive the regional sensible heat flux. If the local-scale advection is comparatively small during the period of the Landsat-7 ETM observation taking place, the development of a Convection Boundary Layer (CBL) may adjust to the surface-disorganized variability at a "blending height", where the atmospheric characteristics become proximately independent of the horizontal position. The corresponding 'effective' surface variables can be determined accordingly (Mason 1988). This approach has proved to be successful for calculating areally averaged surface fluxes in recent reports (e.g., Lhomme et al. 1994; Bastiaassen 1995; Wang et al. 1995; Ma and Tsukamoto 2002b; Ma et al. 2002d; Ma et al. 2003b). Based on this approach, the regional sensible heat flux, $H(x, y)$, can be described as

$$
\begin{aligned}
& H(x, y) \\
& =\rho C_{p} k^{2} u_{B} \frac{T_{s f c}(x, y)-T_{a-B}}{\left[\ln \frac{z_{B}-d_{0}(x, y)}{Z_{0 m}^{\prime}}+k B^{-1}(x, y)-\psi_{h}(x, y)\right] \cdot\left[\ln \frac{z_{B}-d_{0}(x, y)}{Z_{0 m}^{\prime}}-\psi_{m}(x, y)\right]}
\end{aligned}
$$

where $Z_{B}$ is blending height, $u_{B}$ and $T_{a-B}$ is the wind speed and air temperature at the blending height. In this study, $Z_{B}, T_{a-B}$ and $u_{B}$ are determined with the aid of field measurements made by the radio sounding system. We know that the vertical $u$-profile can be measured 
Table 1. Comparison between this paper and SEBAL in estimating sensible heat flux $H(x, y)$.

\begin{tabular}{|l|l|l|}
\hline Variables & \multicolumn{1}{|c|}{ SEBAL } & \multicolumn{1}{c|}{ This paper } \\
\hline $\begin{array}{l}\text { Air temperature } \\
T_{a}(x, y)\end{array}$ & $\begin{array}{l}\text { Air temperature at the reference height } \\
\text { was estimated from } \\
T_{a}(x, y)=f\left(T_{s f c}(x, y)\right)\end{array}$ & $\begin{array}{l}\text { Air temperature at blending height } \\
T_{a-b} \text { was determined using ABL } \\
\text { observations }\end{array}$ \\
\hline $\begin{array}{l}\text { Reference height } z \\
\text { 2.0 }\end{array}$ & $\begin{array}{l}\text { Blending height } z_{b} \text { was determined } \\
\text { using ABL observations }\end{array}$ \\
\hline $\begin{array}{l}\text { Aerodynamic } \\
z_{0 m}(x, y)\end{array}$ & $z_{0 m}(x, y)=f(N D V I(x, y))$ & $\begin{array}{l}\text { Taylor's model (Eq. 15) and land } \\
\text { surface and surface layer } \\
\text { observations }\end{array}$ \\
\hline $\begin{array}{l}\text { Excess resistance to } \\
\text { heat transfer } \\
K B^{-1}(x, y)\end{array}$ & 2.3 & $\begin{array}{l}\text { The relationship between } K B^{-1} \text { and } \\
T_{s f c}\end{array}$ \\
\hline $\begin{array}{l}\text { Zero-plane } \\
\text { displacement } d_{0}(x, y)\end{array}$ & $d_{0}=(2 / 3) h_{v}$ & $d_{0}=f(L A I)$ (Eq. 16) \\
\hline
\end{tabular}

using a radio sounding system; that is, $u$ changing with the height can be determined. Normally, wind speed increases with height, and becomes a constant at height $Z$. The wind speed measured using a radio sounding system at the height $Z$ is called $u_{B}$ and the height $Z$ is named $Z_{B}$ here. The air temperature at the blending height, $Z_{B}$, is $T_{a-B}$. Effective aerodynamic roughness, $Z_{0 m}^{\prime}$, in Eq. 14 over the CAMP/Tibet area includes the effect of topography and low vegetation (e.g., grass). It is calculated by using Taylor's model (Taylor et al. 1989), i.e.:

$$
\ln \left(\frac{Z_{0 m}^{\prime}}{Z_{0 m}}\right)=3.5\left(a \frac{2 \pi}{\lambda_{1}}\right)^{2} \ln \left(\frac{\lambda_{1}}{Z_{0 m}}\right)
$$

where $a$ is the amplitude of relief and $\lambda_{1}$ is the wavelength of periodic relief. In other words, the local roughness length, $Z_{0 m}$, over the experiment area can be determined using the turbulent measurements of an anemometerthermometer (Ma et al. 2002a). Then the effective aerodynamic roughness length, $Z_{0 m}^{\prime}$, can be determined from Eq. 15. The excess resistance to heat transfer, $k B^{-1}$, is shown as a function of surface temperature over the Tibetan Plateau area, and $k B^{-1}(x, y)=0.52\left(T_{s f c}(x, y)-\right.$ $\left.T_{\text {air }}(x, y)\right)-1.85$ (Ma et al. 2002a). $d_{0}$ is a zeroplane displacement, which can be calculated from the leaf area index (LAI) using Raupach's model (Raupach 1994), i.e.:

$$
1-\frac{d_{0}(x, y)}{h(x, y)}=\frac{1-\exp \left(-\sqrt{c_{d 1} L A I(x, y)}\right)}{\sqrt{c_{d 1} L A I(x, y)}}
$$

where $h$ is the vegetation height, and it is $10 \mathrm{~cm}$ over our experimental area. $c_{d 1}$ in Eq. 16 is a free parameter, and for a range of partial vegetation cover, Raupach (1994) proposed to use $c_{d 1}=7.5$. $L A I$ was determined from vegetation coverage (Kustas and Norman 1997). In other words, $L A I=-2 \ln \left(1-P_{v}\right) . \psi_{h}(x, y)$ and $\psi_{m}(x, y)$ in Eq. 14 are the integrated stability functions. For unstable conditions, the integrated stability functions, $\psi_{h}(x, y)$ and $\psi_{m}(x, y)$, can be written as (Paulson 1970)

$$
\left\{\begin{aligned}
\psi_{m}(x, y)= & 2 \ln [(1+X) / 2] \\
& +\ln \left[\left(1+X^{2}\right) / 2\right] \\
& -2 \arctan (X)+0.5 \pi \\
\psi_{h}(x, y)= & 2 \ln \left[\left(1+X^{2}\right) / 2\right]
\end{aligned}\right.
$$

where $X=\left\{1-16\left[z-d_{0}(x, y)\right] / L(x, y)\right\}^{0.25}$. For stable conditions, the integrated stability functions $\psi_{m}(x, y)$ and $\psi_{h}(x, y)$ become (Webb 1970)

$$
\begin{aligned}
\psi_{m}(x, y) & =\psi_{h}(x, y) \\
& =-5\left[z-d_{0}(x, y)\right] / L(x, y)
\end{aligned}
$$

The stability function $\left[z-d_{0}(x, y)\right] / L(x, y)$ is calculated by Businger's method (Businger, 1988).

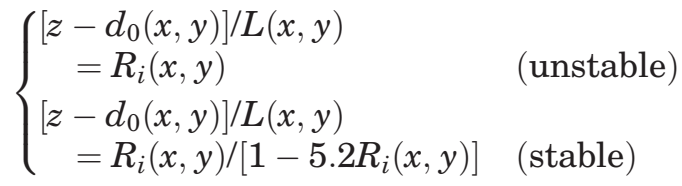

where $R_{i}(x, y)$ is the Richardson number, by the definition of Richardson number. The approxi- 

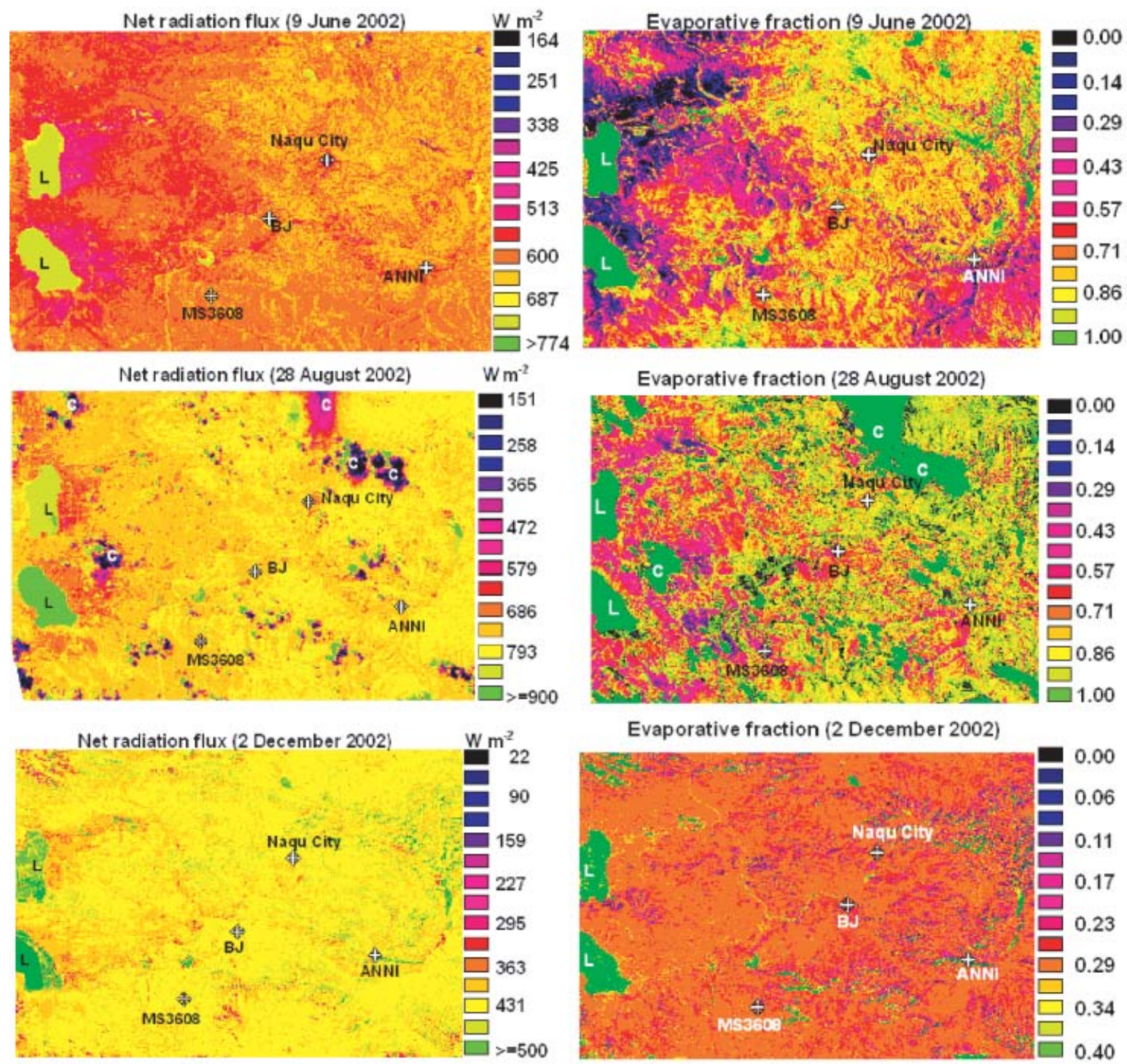

Evaporative fraction (2 December 2002)
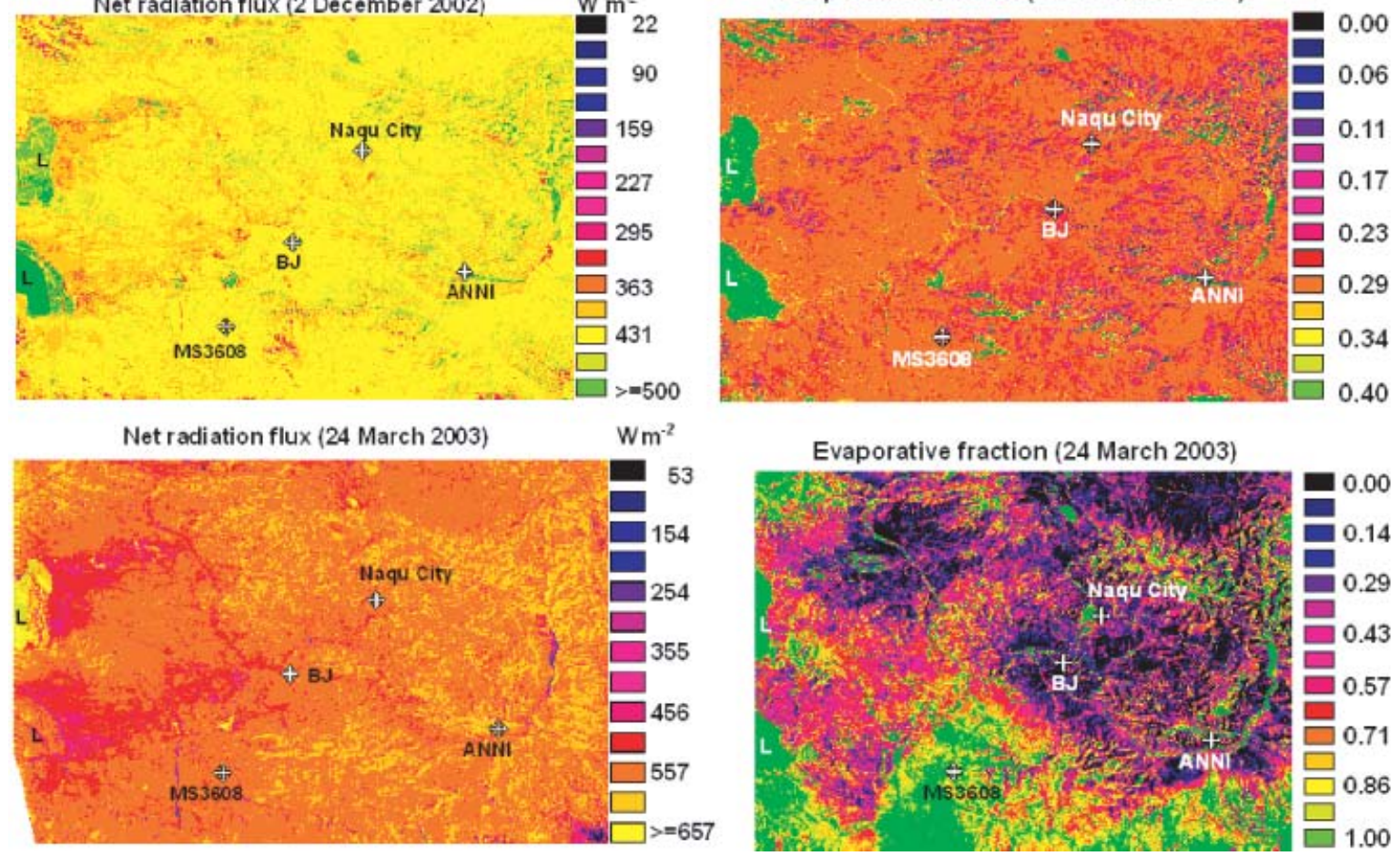

Fig. 4. Distribution of evaporative fraction $(E F)$ over the CAMP/Tibet area. 
mate analytical solutions of $R_{i}$ found by Yang et al. (2001) will be used here.

The difference between this paper and the SEBAL model (Bastiaanssen 1995) in estimating the sensible heat flux, $H(x, y)$, is shown in Table 1 . The advantages of the method presented in this paper will be documented through the following case studies.

\section{Latent heat flux}

The regional latent heat flux $\lambda E(x, y)$ can be derived as the residual of the energy budget theorem for land surface based on the condition of zero horizontal advection at $z<z_{\text {sur }}$, i.e.:

$$
\lambda E(x, y)=R_{n}(x, y)-H(x, y)-G_{0}(x, y)
$$

$b$ Evaporative fraction $\mathrm{EF}$

If the evaporative fraction $(E F)$ defining equation (Eq. 1) is used to the ETM pixel scale, it will become

$$
\Lambda(x, y)=\frac{\lambda E(x, y)}{H(x, y)+\lambda E(x, y)}
$$

The $E F$ value is between 0.0 and 1.0. $\Lambda$ equaling 0.0 means that the surface is very dry (e.g., the very dry sand desert surface), and there is no evapotranspiration from the surface. $\Lambda$ equaling 1.0 means that surface is very wet (e.g. water surface), and there is maximum evapotranspiration from the surface.

\section{Case studies and validation}

Figure 4 shows the distribution maps of $E F$ over the partly heterogeneous surface of the CAMP/Tibet area (see the dash frame on the CAMP Meso Scale Map of Fig. 1). The distribution maps of net radiation flux are also shown in Fig. 4 (the others were omitted). The frequency distributions of net radiation flux and $E F$ are shown in Fig. 5. Figure 4 is based on $3400 \times 2000$ pixels. Derived EFs are validated using field measurements. Since it is difficult to determine where the exact locations of the experimental sites are, the values of a $5 \times 5$ pixel rectangle, surrounding the determined Universal Transverse Mercator (UTM) coordinate, are compared with the field measurements. The EFs derived from Landsat-7 ETM data were compared with the field measurements at the BJ and ANNI sites and are shown in Fig. 6 and Table 2. The derived surface temperature and land surface heat fluxes (net radi- ation flux, $R_{n}$, soil heat flux, $G_{0}$, sensible heat flux, $H$, and latent heat flux, $\lambda E$ ) were also compared with the field measurements at BJ and ANNI sites; they are also shown in Table 2. The absolute percent difference $(A P D)$ can quantitatively measure the difference between the derived results, $\left(V_{\text {derived }(i)}\right)$, and measured values, $\left(V_{\text {measured }(i)}\right)$, as

$$
A P D=\frac{\left|V_{\text {derived }(i)}-V_{\text {measured }(i)}\right|}{V_{\text {measures }(i)}}
$$

BJ station $\left(31.37^{\circ} \mathrm{N}, 91.90^{\circ} \mathrm{E}, 4534 \mathrm{~m}\right.$ ASL $)$ and ANNI station $\left(31.25^{\circ} \mathrm{N}, 92.17^{\circ} \mathrm{E}, 4480 \mathrm{~m}\right.$ ASL) of the CAMP/Tibet have been conducted successfully on the Naqu area located in the central Tibetan Plateau. Its surface is essentially flat and open. Prior to the Asia summer monsoon period, the surface is very dry and covered by dry grass; as the surface becomes wet at the onset of the Asia summer monsoon, the grasses starts grow. The turbulent fluxes measurements (BJ: KAIJO-DA600; ANNI: CSAT3) were as set up at $20 \mathrm{~m}$ above the ground at two stations. The density of water vapor and concentration of carbon dioxide was obtained by LI-7500. The instruments respond quickly for gathering information, also can be stably used over a long period of time in the field. The data logger system is the control system (CR5000). The measurement frequency of the eddy system is $10 \mathrm{~Hz}$, and the flux data is output every 30 minutes.

The results show that:

(1) The derived evaporative fractions $(E F s)$ in the four different months over the study area are in good accordance with the land surface status. The experimental area includes a variety of land surfaces such as a large area of grassy marshland, some desertification grassland areas, many small rivers and several lakes; therefore, these derived parameters show a wide range due to the strong contrast of the surface features. A quite large probability of $E F=1$ values in June, August and March (Fig. 5) show that there is much water surface (lakes, small pool and rivers) over the study area during these times. The EFs around a lake in the distribution maps are much lower in June and August. The reason is that most of the area around the lake is desertification type grass land, and was dry with low moisture in June and August. 

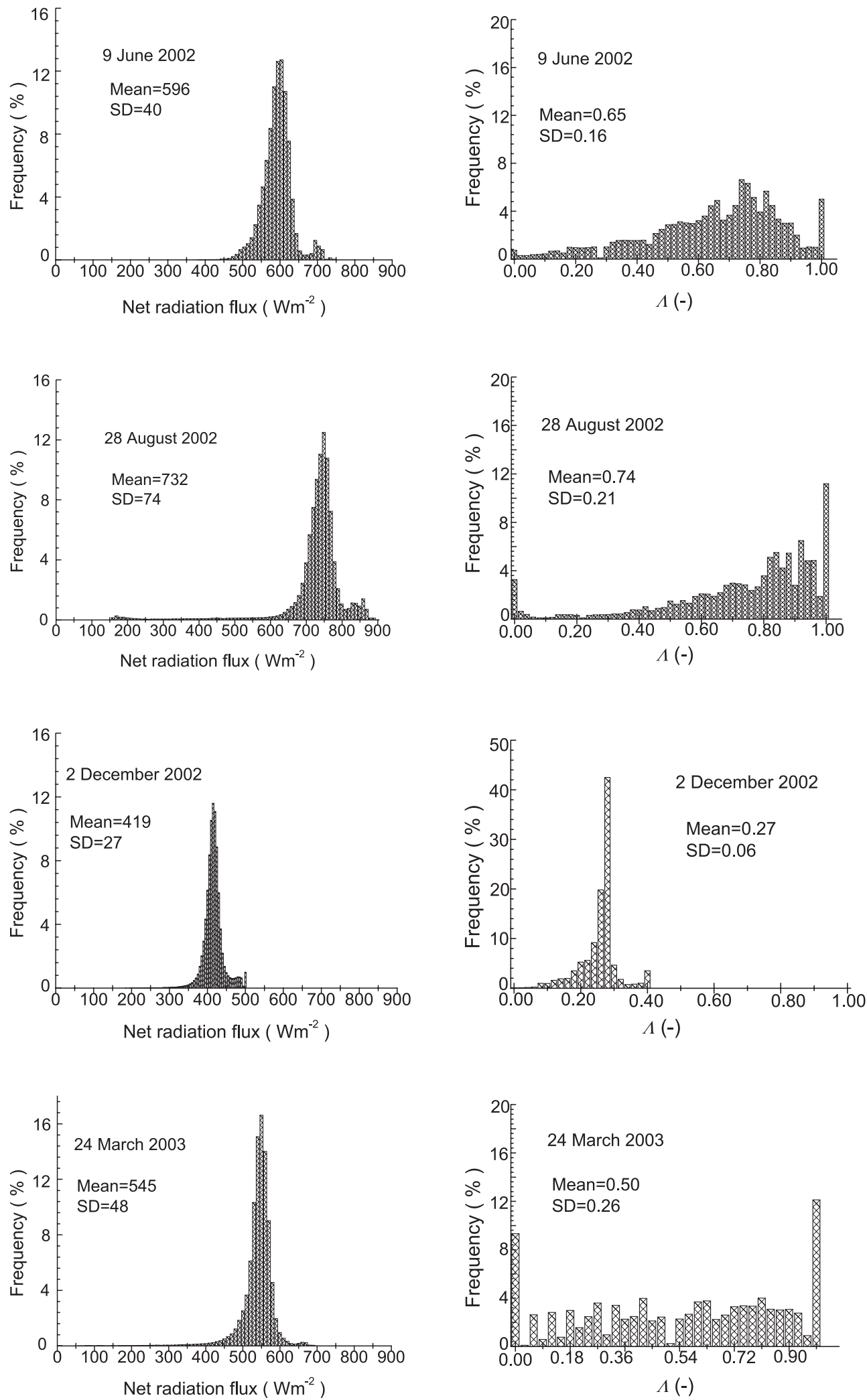

Fig. 5. Frequency distribution of evaporative fraction $(E F)$ over the CAMP/Tibet area. 

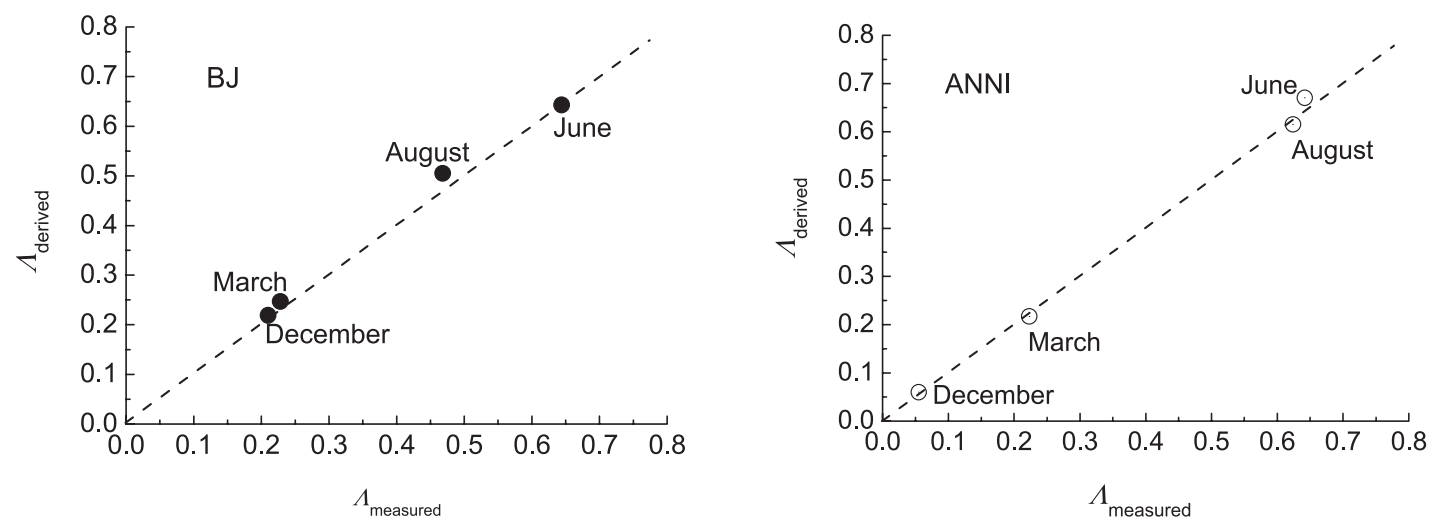

Fig. 6. Comparison of derived results with field measurements for the evaporative fraction over the CAMP/Tibet area, together with a 1:1 line.

(2) The derived pixel value and average value (Figs. 4 and 5) of EFs in June and August are higher than those in December and March. $E F s$ in June and August are mostly from 0.60 to 1.0 , and $E F s$ in December are mostly around 0.25 . This means that there is much more evaporation in summer and autumn than in winter and spring in the central Tibetan Plateau area. The reason is that most the land surface is covered by green grass in summer and autumn but by snow and ice during winter and spring in the experimental area. That is, sensible heat and latent heat fluxes play different roles in the partitioning of the net radiation flux in different months in the Tibetan Plateau: sensible heat flux plays the main role in December and March, while latent heat flux plays the main role in June and August.

(3) Because the land surface cover and property in March is very complex (with ice, snow, seasonal and long-living permafrost, grasslands and lakes, etc., existing in this month), the distribution of EFs in this month is thus complicated.

(4) The derived regional EFs with APD less than $9.5 \%$ at validation sites in the CAMP/ Tibet area is in good agreement with field measurements (Fig. 6 and Table 2). The reason is that the radiation transportation processes and the process in the atmospheric boundary layer were considered in more detail by our methodology. The results demonstrate that our proposed parameterization methodology for $E F$ is reasonable and it can be used over the central Tibetan Plateau area.

\section{Concluding remarks}

In this study, a parameterization methodology to estimate the regional distribution of evaporative fraction $(E F)$ for the determination of regional distributions of evapotranspiration over heterogeneous landscapes was proposed using Landsat-7 ETM data and field observations. We then applied it to the central Tibetan Plateau area. The derived results over our study area were found to be reasonable. Thus our method provides a sound basis to study evapotranspiration and land surface fluxes over a heterogeneous landscape.

Dealing with regional evapotranspiration and land surface heat fluxes over heterogeneous landscapes is not easy. The parameterization method presented in this study is still undergoing development:

1) Only four Landsat-7 ETM images, each at a specific time of a specific day are used in this study. To obtain more accurate regional evapotranspiration and land surface fluxes, their seasonal variations and even daily variations over the CAMP/Tibet area, or indeed the whole Tibetan Plateau area, more field observations (PBL tower and radiation measurement system, AWS, radio sonde system, turbulent fluxes measured by eddy-correlation technique, soil moisture and soil temperature measurement system, etc.) and another satellite data such as MODIS (Moderate Resolution Imaging Spectroradiometer) and NOAA (National Oceanic and Atmospheric Administration)/AVHRR (Advanced Very High Resolution Radiometer) will 
Table 2. Comparison of the derived surface temperatures, surface heat fluxes and evaporative fraction (Cal.) versus values measured (Meas.) at the CAMP/Tibet site with APD.

\begin{tabular}{|c|c|c|c|c|c|c|c|c|}
\hline \multicolumn{9}{|c|}{$T_{s f c}\left[{ }^{\circ} \mathrm{C}\right]$} \\
\hline & \multicolumn{2}{|c|}{ June } & \multicolumn{2}{|c|}{ August } & \multicolumn{2}{|c|}{ December } & \multicolumn{2}{|c|}{ March } \\
\hline & BJ & ANNI & BJ & ANNI & BJ & ANNI & BJ & ANNI \\
\hline Cal. & 28.0 & 31.0 & 17.0 & 16.0 & -26.0 & -25.0 & 6.0 & 5.0 \\
\hline Meas. & 26.5 & 28.8 & 18.5 & 17.0 & -27.8 & -23.6 & 5.6 & 4.8 \\
\hline$A P D$ & $5.7 \%$ & $7.6 \%$ & $8.1 \%$ & $5.9 \%$ & $6.5 \%$ & $5.9 \%$ & $7.1 \%$ & $4.2 \%$ \\
\hline \multicolumn{9}{|c|}{$R_{n}\left[\mathrm{~W} \mathrm{~m}{ }^{-2}\right]$} \\
\hline & \multicolumn{2}{|c|}{ June } & \multicolumn{2}{|c|}{ August } & \multicolumn{2}{|c|}{ December } & \multicolumn{2}{|c|}{ March } \\
\hline & BJ & ANNI & BJ & ANNI & BJ & ANNI & BJ & ANNI \\
\hline Cal. & 562 & 565 & 540 & 684 & 380 & 403 & 413 & 548 \\
\hline Meas. & 540 & 542 & 506 & 662 & 357 & 385 & 385 & 520 \\
\hline$A P D$ & $4.1 \%$ & $4.2 \%$ & $6.7 \%$ & $3.3 \%$ & $6.4 \%$ & $4.7 \%$ & $7.3 \%$ & $5.4 \%$ \\
\hline \multicolumn{9}{|c|}{$G_{0}\left[\mathrm{~W} \mathrm{~m} \mathrm{~m}^{-2}\right]$} \\
\hline & \multicolumn{2}{|c|}{ June } & \multicolumn{2}{|c|}{ August } & \multicolumn{2}{|c|}{ December } & \multicolumn{2}{|c|}{ March } \\
\hline & BJ & ANNI & BJ & ANNI & BJ & ANNI & $\mathrm{BJ}$ & ANNI \\
\hline Cal. & 105 & 104 & 154 & 152 & 74 & 73 & 85 & 83 \\
\hline Meas. & 98 & 99 & 147 & 142 & 69 & 68 & 79 & 78 \\
\hline$A P D$ & $7.1 \%$ & $5.1 \%$ & $4.8 \%$ & $7.0 \%$ & $7.2 \%$ & $7.4 \%$ & $7.6 \%$ & $6.4 \%$ \\
\hline \multicolumn{9}{|c|}{$H\left[\mathrm{~W} \mathrm{~m}^{-2}\right]$} \\
\hline & \multicolumn{2}{|c|}{ June } & \multicolumn{2}{|c|}{ August } & \multicolumn{2}{|c|}{ December } & \multicolumn{2}{|c|}{ March } \\
\hline & BJ & ANNI & BJ & ANNI & BJ & ANNI & BJ & ANNI \\
\hline Cal. & 163 & 152 & 191 & 205 & 239 & 310 & 247 & 364 \\
\hline Meas. & 157 & 158 & 216 & 211 & 234 & 326 & 257 & 345 \\
\hline$A P D$ & $3.8 \%$ & $3.8 \%$ & $6.9 \%$ & $2.8 \%$ & $2.1 \%$ & $4.9 \%$ & $3.9 \%$ & $5.5 \%$ \\
\hline \multicolumn{9}{|c|}{$\lambda E\left[\mathrm{~W} \mathrm{~m}^{-2}\right]$} \\
\hline & \multicolumn{2}{|c|}{ June } & \multicolumn{2}{|c|}{ August } & \multicolumn{2}{|c|}{ December } & \multicolumn{2}{|c|}{ March } \\
\hline & BJ & ANNI & BJ & ANNI & BJ & ANNI & BJ & ANNI \\
\hline Cal. & 294 & 309 & 195 & 327 & 67 & 20 & 81 & 101 \\
\hline Meas. & 284 & 283 & 190 & 350 & 62 & 19 & 76 & 99 \\
\hline$A P D$ & $3.5 \%$ & $9.2 \%$ & $2.6 \%$ & $6.6 \%$ & $8.1 \%$ & $5.3 \%$ & $6.6 \%$ & $2.0 \%$ \\
\hline \multicolumn{9}{|c|}{$\Lambda[-]$} \\
\hline & \multicolumn{2}{|c|}{ June } & & & De & ber & & \\
\hline & BJ & ANNI & BJ & ANNI & BJ & ANNI & BJ & ANNI \\
\hline Cal. & 0.643 & 0.670 & 0.505 & 0.615 & 0.219 & 0.060 & 0.247 & 0.217 \\
\hline Meas. & 0.644 & 0.642 & 0.468 & 0.624 & 0.210 & 0.055 & 0.228 & 0.233 \\
\hline$A P D$ & $0.16 \%$ & $4.40 \%$ & $7.90 \%$ & $1.44 \%$ & $4.29 \%$ & $9.10 \%$ & $8.33 \%$ & $2.69 \%$ \\
\hline
\end{tabular}


have to be used. It will also be worthwhile to apply the SEBI (Surface Energy Balance Index, Menenti and Choudhury 1993) method and SEBS (Surface Energy Balance System, Su 2002).

2) This study implies that the parameterization method is only applicable to clear-sky days (to apply MODTRAN and detect surface temperature). To extend its applicability to cloudy skies, we should consider using microwave remote sensing to derive surface temperatures and other land surface variables.

We intend to undertake all these works in our ongoing studies.

\section{Acknowledgements}

This work was under the auspices of the Chinese National Key Programme for Developing Basic Sciences (2005CB422003), the National Natural Science Foundation of China (40520140126 and 40675012), the Innovation Project of Chinese Academy of Sciences (KZCX3-SW-231) and the CAMP/Tibet project founded by Japan Science and Technology Agency (JST). Most of this work was done at Alterra, Wageningen University and Research Center, The Netherlands (it was supported by the EC FP6 GMES EAGLE project (contract no. 502057)) and the International Institute for Geo-Information Science and Earth Observation, The Netherlands. The authors thank all the scientists in the CAMP/Tibet group from China and Japan for their hard work collecting field data.

\section{References}

Bastiaanssen, W.G.M., 1995: Regionalization of surface flux densities and moisture indicators in composite terrain. $\mathrm{PhD}$ thesis, Wageningen Agricultural University, Wageningen, the Netherlands, 143-161.

Businger, J.A., 1988: A note on the Businger-Dyer profiles. Bound-Layer Meteor., 42, 145-151.

Carlson, T.N. and D.A. Ripley, 1997: On the relation between NDVI, fractional vegetation cover, and leaf area index. Remote Sens. Environ., 62, 241-252.

Choi, T., J. Hong, J. Kim, H. Lee, J. Asanuma, H. Ishikawa, O. Tsukamoto, Z. Gao, Y. Ma, K. Ueno, J. Wang, T. Koike, and T. Yasunari, 2004: Turbulent exchange of heat, water vapor, and momentum over a Tibetan prairie by eddy covariance and flux variance measurements.
J. Geophys. Res., 109(D21106), 10.1029/ 2004JD004767.

Choudhury, B.J., S.B. Idso, and R.J. Reginato, 1987: Analysis of an empirical model for soil heat flux under a growing wheat crop for estimating evaporation by infrared-temperature based energy balance equation. Agric. For. Meteor., 39, 283-297.

Choudhury, B.J. and J.L. Monteith, 1988: A fourlayer model for the heat budget of homogeneous land surfaces, Quart. J. Roy-Meteor. Soc., 114, 373-398.

Churkina, G., S.W. Running, A.L. Schloss, and the Participants of the Potsdam NPP Model Intercomparison, 1999: Comparing global models of terrestrial net primary productivity (NPP): the importance of water availability. Global Change Biology, 5(Suppl. 1), 46-55.

Clothier, B.E., K.L. Clawson, P.J. Pinter, M.S. Moran, R.J. Reginato, and R.D. Jackson, 1986: Estimating of soil heat flux from net radiation during the growth of alfalfa. Agric. For. Meteor., 37, 319-329.

Crago, R.D., 1996: Comparison of the evaporative fraction and the Priestley-Taylor a for parameterizing daytime evaporation. Water Resources Research, 32(5), 1403-1409.

Daughtry, C.S.T., W.P. Kustas, M.S. Moran, P.J. Pinter, R.D. Jackson, P.W. Brown, W.D. Nichols, and L.W. Gay, 1990: Spectral estimates of net radiation and soil heat flux. Remote Sens. Environ., 32, 111-124.

Kenizys, F.X., L.W. Abreu, G.P. Anderson, J.H., Chetwynd, E.P. Shettle, A. Berk, L.S. Bernstein, D.C. Robertson, P. Acharya, L.S. Rothman, J.E.A. Selby, W.O. Gallery, and S.A. Clough, 1996: The MODTRAN3/2 report and LODTRAN 7 Model. [L.W. Abreu and G.P. Andson, (eds.)], Ontar Corp., North Andover, MA, for Phillips Laboratory, Geophysical Directorate, Hanscom AFB, MA, Contract No. F19628-91-C-0132.

Koepke, P., K.T. Kriebel, and B. Dietrich, 1985: The effect of surface reflection and of atmospheric parameters on the short wave radiation budget. Adv. Space Res., 5, 353-354.

Kustas, W.P. and C.S.T. Daughtry, 1990: Estimation of the soil heat flux/net radiation ratio from spectral data. Agric. For. Meteor., 39, 205-223.

Kustas, W.P. and J.M. Norman, 1997: A two-source approach for estimating turbulent fluxes using multiple angle thermal infrared observations. Water Resources Research, 33, 1495-1508.

Lhomme, J.-P., A. Chehbouni, and B. Monteny, 1994: Effective parameters of surface energy balance in heterogeneous landscape. Bound.-Layer Meteor., 71, 297-310. 
Ma, Y., J. Wang, M. Menenti, and W.G.M. Bastiaanssen, 1999: Estimation of fluxes over the heterogeneous land surface with the aid of satellite remote sensing and field observation. ACTA Meteor. Sinica, 57, 180-189, (in Chinese with English abstract).

Ma, Y., O. Tsukamoto, J. Wang, H. Ishikawa, and I. Tamagawa, 2002a: Analysis of aerodynamic and thermodynamic parameters over the grassy marshland surface of Tibetan Plateau, Progress in Natural Sci., 12, 36-40.

$\mathrm{Ma}, \mathrm{Y}$. and O. Tsukamoto, 2002b: Combining satellite remote sensing with field observations for land surface heat fluxes over inhomogeneous landscape, China Meteorological Press, Beijing, China.

Ma, Y., Z. Su, Z.-L. Li, T. Koike, and M. Menenti, 2002c: Determination of regional net radiation and soil heat flux densities over heterogeneous landscape of the Tibetan Plateau. Hydrological Processes, 16(15), 2963-2971.

Ma, Y., O. Tsukamoto, H. Ishikawa, Z. Su, M. Menenti, J. Wang, and J. Wen, 2002d: Determination of Regional land surface heat flux densities over heterogeneous landscape of HEIFE Integrating satellite remote sensing with field observations. J. Meteor. Soc. Japan, 80(3), 485-501.

Ma, Y., Z. Su, T. Koike, T. Yao, H. Ishikawa, K. Ueno, and M. Menenti, 2003a: On measuring and remote sensing surface energy partitioning over the Tibetan Plateau-from GAME/Tibet to CAMP/Tibet. Physics and Chemistry of the Earth, 28, 63-74.

Ma, Y., H. Ishikawa, O. Tsukamoto, M. Menenti, Z. Su, T. Yao, T. Koike, and T. Yasunari, 2003b: Regionalization of surface fluxes over heterogeneous landscape of the Tibetan Plateau by using satellite remote sensing. J. Meteor. Soc. Japan, 81(2), 277-293.

Ma, Y., S. Fan, H. Ishikawa, O. Tsukamoto, T. Yao, T. Koike, H. Zuo, Z. Hu, and Z. Su, 2005: Diurnal and inter-monthly variation of land surface heat fluxes over the central Tibetan Plateau area. Theoretical and Applied Climatology, 80, 259-273.

Mason, P., 1988: The formation of areally averaged roughness lengths. Quart. J. Roy. Meteor. Soc., 114, 399-420.

Menenti, M., W.G.M. Bastiaanssen, and D. Van Eick, 1989: Determination of hemispheric reflectance with Thematic Mapper data, Remote Sens. Environ., 28, 327-337.

Menenti, M., W.G.M. Bastiaanssen, K. Hefny, and M.H. Abd EI Karim, 1991: Mapping of ground water losses by evaporation in the Western Desert of Egypt. DLO Winand Staring Centre,
Report no. 43, Wageningen, The Netherlands, $1-116$.

Menenti, M. and B.J. Choudhury, 1993: Parameterization of land surface evaporation by means of location dependent potential evaporation and surface temperature range. In: Exchange processes at the land surface for a range of space and time scales. [Bolle, Feddes and Kalma, (eds.)], IAHS Publ., 212, 561-568.

Paulson, C.A., 1970: The mathematic representation of wind speed and temperature profiles in the unstable atmospheric surface layer. J. Appl. Meteor., 9, 856-861.

Raupach, M.R., 1994: Simplified expressions for vegetation roughness length and zero-plane displacements as functions of canopy height and area index. Bound.-Layer Meteor., 71, 211-216.

Shuttleworth, W.J., R.J. Gurney, A.Y. Hsu, and J.P. Ormsby, 1989: FIFE: the variation in energy partition at surface flux sites. IAHS Publication, 186, 67-74.

Sugita, M. and W. Brutsaert, 1991: Daily evaporation over a region from lower boundary-layer profiles measured with radiosondes. Water Resources Research, 27(5), 747-752.

Su, Z., 2002: The Surface Energy Balance System (SEBS) for estimation of turbulent heat fluxes. Hydrology and Earth System Sci., 6, 85-99.

Taylor, P.A., R.I. Sykes, and P.J. Mason, 1989: On the parameterization of drag over small scale topography in neutrally stratified Boundary flow. Bound.-Layer Meteor., 48, 409-422.

Valor, E. and V. Caselles, 1996: Mapping land surface emissivity from NDVI: application to European, African, and South American areas. Remote Sens. Environ., 57, 167-184.

Verhoef, W., 1997: Theory of radiative transfer models applied in optical remote sensing of vegetation canopies. $\mathrm{PhD}$ thesis, Remote Sensing Department of National Aerospace Laboratory, The Netherlands, $290 \mathrm{pp}$.

Wang, J., Y. Ma, M. Menenti, W.G.M. Bastiaanssen, and Y. Mistsuta, 1995: The scaling-up of processes in the heterogeneous landscape of HEIFE with the aid of satellite remote sensing, J. Meteor. Soc. Japan., 73, 1235-1244.

Webb, E.K., 1970: Profile relationships: the log-liner range and extension to strong stability. Quart. J. Roy. Meteor. Soc., 96, 67-90.

Wen, J., 1999: Land surface variables estimated from remote sensing and the correction of atmospheric effects. Ph.D. Thesis, Lanzhou Institute of Plateau Atmospheric Physics, The Chinese Academy of Sciences, Lanzhou, China, 115 pp, (in Chinese with English abstract).

Yang, K., N. Tamai, and T. Koike, 2001: Analytical 
solution of surface layer similarity equations. J. Appl. Meteorol., 40, 1647-1653.

Yang, K., T. Koike, H. Fujii, K. Tamagawa, and N. Hirose, 2002: Improvement of surface flux parameterizations with a turbulence-related length. Quart. J. Roy. Meteor. Soc., 128B, 2073-2088.

Yang, K., T. Koike, and D. Yang, 2003: Surface flux parameterization in the Tibetan Plateau.
Bound.-Layer Meteor., 116, 245-262.

Yang, K., T. Koike, H. Ishikawa, and Y. Ma, 2004: Analysis of the surface energy budget at a site of GAME/Tibet using a single-source model. $J$ Meteor Soc of Japan., 82, 131-153.

Zuo, H., Y. Hu, D. Li, S. Lu, and Y. Ma, 2005: Seasonal transition and its boundary characteristics in Amdo area of Tibetan Plateau. Progress in Natural Sci., 15, 239-245. 